\title{
Use of the flinch-jump technique to study narcotic analgesia in the rat
}

\author{
RANDALL D. YOUNG, BEVERLY E. THORN, ROBERT A. LEVITT, \\ and MAXINE J. WEYANT \\ Department of Psychology and School of Medicine, Southern Illinois University \\ Carbondale, Illinois 62901
}

\begin{abstract}
The flinch-jump technique was adapted to allow single-session within-subject evaluation of narcotic analgesia and its blockade by a narcotic antagonist. The first experiment was a doseresponse study of morphine-induced analgesia employing this methodology. The second experiment was a dose-response study of the inhibition of morphine-analgesia by systemic injection of the narcotic antagonist naloxone. Morphine $(2.5,5.0,10.0 \mathrm{mg} / \mathrm{kg})$ produced a dose-response analgesia, while injection of saline or naloxone alone failed to alter jump thresholds. Injections of 0.1 or $1.0 \mathrm{mg} / \mathrm{kg}$ naloxone systemically reversed the analgesia produced by $10 \mathrm{mg} / \mathrm{kg}$ morphine.
\end{abstract}

The narcotic analgesics, of which morphine is a prototype, are an important group of behaviorally active drugs. This importance stems from their useful analgesic action, as well as from their mood-altering properties and ability to produce physical dependence and its attendant abstinence syndrome in a dependent organism (Jaffe, 1975). A considerable amount of research has been directed at analyzing the analgesic action of narcotics, including the biochemical and neurological bases of this action (Criswell \& Levitt, 1975; Jaffe \& Martin, 1975).

Many studies of narcotic analgesia have employed the laboratory rat as a model system. Techniques commonly employed to administer a painful stimulus to the rat for the study of narcotic analgesia include the flinchjump technique (Bonnet \& Peterson, 1975; Evans, 1961; Jacquet \& Lajtha, 1973), the hot-plate method (Sharpe, Garnett, \& Cicero, 1974), the tail-flick test (Collins, Wei, \& Way, 1974; D'Amour \& Smith, 1941), and a multiitem test battery which includes measuring responsivity to auditory, visual, and light tactile stimuli, as well as hemostat pinches, pin pricks, and hot and cold plates (Jacquet \& Lajtha, 1974).

Although each approach has its own advantages and disadvantages, we have chosen to further investigate the use of the flinch-jump technique. Previous studies have compared flinch-jump thresholds of separate groups of drug-treated and control animals (Bonnet \& Peterson, 1975; Evans, 1961; Jacquet \& Lajtha, 1973). The present studies employ the flinch-jump technique to evaluate the analgesic action of morphine, and its antagonism by pharmacological manipulation among individual subjects and within one brief test session 1-2 h in length.

Send reprint requests to $R$. A. Levitt, who is now at the Department of Psychology, University of Alabama in Birmingham, Birmingham, Alabama 35294.

\section{GENERAL METHODS}

\section{Subjects}

Adult Long-Evans-strain rats of both sexes (weighing 250 to $400 \mathrm{~g}$ ) served as subjects. The animals were housed individually with free access to food and water, except during testing. The subjects were maintained on a 12 -h alternating light-dark cycle. Flinch-jump testing was confined to the light part of the cycle. Each subject was used only once, during a 1-2-h test session (average session length was $1 \frac{1 / 2}{h}$ ), and served as its own control.

\section{Drugs}

Morphine sulfate and naloxone hydrochloride were the test drugs, while isotonic sodium chloride was used as the vehicle. Morphine and naloxone were administered as solutions in isotonic sodium chloride.

\section{Flinch-Jump Testing}

The flinch-jump tests were carried out in a compartment, $20.5 \times 30 \times 19.5 \mathrm{~cm}$, with a grid floor of stainless steel rods. The shock source was a constant current ac shocker (Lafayette Instruments Model A-615AR) coupled to the grid floor through a neon scrambler (Lafayette Instruments Model 85152).

Each experiment consisted of three series of flinch-jump tests. The second series was conducted $30 \mathrm{~min}$ after the end of the first, and the third series was conducted $10 \mathrm{~min}$ after the end of the second. These intervals were selected to allow for onsets of drug action as detailed below.

Within each of the three series, five trials of flinch-jump tests were administered. Each trial consisted of an ascending, followed by a descending, series of 1-sec footshocks delivered at $30-\mathrm{sec}$ intervals. Initial shock intensity was $0.025 \mathrm{~mA}$. Shock intensity was increased through the following steps, $0.05,0.1$, $0.2,0.3,0.4,0.5,0.6,0.7$, and $0.8 \mathrm{~mA}$, until a jump response (a shock-contingent response characterized by the simultaneous lifting of at least three paws off the grid floor) was observed. This criterion for a jump response is equivalent to Category 4 of Bonnet and Peterson (1975). At the first appearance of a jump response, a descending shock sequence was begun until no shock-contingent behavior (no flinch/no crouch, startle, or twitch) was observed. This procedure was continued until five such flinch-jump tests, constituting one series, were completed. For each ascending sequence, the shock intensity eliciting a jump was recorded, and for each descending sequence, the 
lowest shock intensity eliciting a flinch was recorded. These five jump and flinch intensities were each averaged to produce an estimate of flinch and jump threshold for each test series.

\section{EXPERIMENT 1}

This was a dose-response study of morphine-induced analgesia. A naloxone group was also included, because of the use of this drug in Experiment 2.

\section{Method}

There were five groups of eight subjects. Each group was given an initial series of five flinch-jump tests, followed by an immediate intraperitoneal (IP) injection of 2.5, 5.0, or $10.0 \mathrm{mg} / \mathrm{kg}$ morphine, $1.0 \mathrm{mg} / \mathrm{kg}$ naloxone, or the vehicle. Injection volumes ranged between 0.25 and $0.40 \mathrm{ml}$. Thirty minutes later, a second flinch-jump series was administered, followed in $10 \mathrm{~min}$ by a third flinch-jump series.

\section{Results}

Thresholds for the five groups of animals during the baseline series ranged between 0.05 and $0.06 \mathrm{~mA}$ for flinch and 0.20 and $0.25 \mathrm{~mA}$ for jump. Flinch thresholds were not affected by the drug injections and ranged between 0.05 and $0.07 \mathrm{~mA}$ during the two retest series, consistent with some (Evans, 1961), but not all (Bonnet \& Peterson, 1975), previous reports.

The data from this experiment are shown in Figure 1. In order to better compare drug effects on jump thresholds, group baseline thresholds were set at zero and milliampere deviations from this value during the first and second postdrug test series were plotted. It can be seen in Figure 1 that morphine produced a doseresponse analgesia, while saline or naloxone failed to alter jump thresholds. This interpretation was confirmed by statistical analysis.

Two one-way ANOVAs were used to analyze the data. The first analysis was based on difference scores between baseline and the analgesia test. The overall $F$ showed that there were differences among the group means, $F(4,35)=8.62, p<.01$. Linear trend analysis confirmed that the morphine analgesia was dose-dependent,

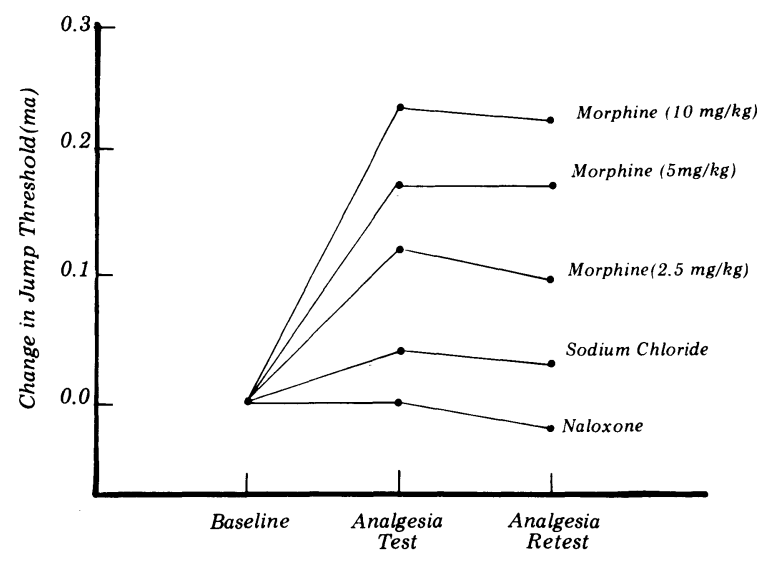

Figure 1. Morphine-induced analgesia.

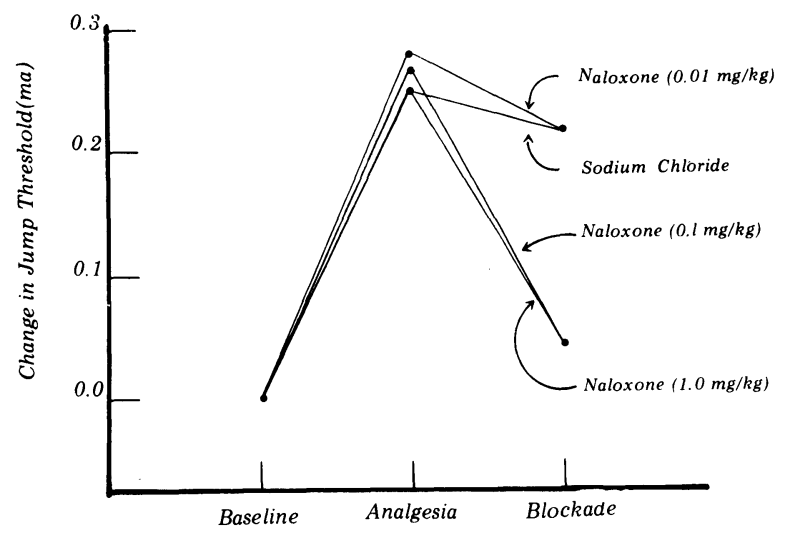

Figure 2. Blockade of morphine-induced analgesia by naloxone administered systemically.

$\mathrm{F}(1,28)=45.85, \mathrm{p}<.01$. Post hoc analysis (NewmanKeuls) showed significant analgesia for $5 \mathrm{mg} / \mathrm{kg}$, $1.22>\mathrm{CR}_{\mathrm{n}-\mathrm{k}}(1.14), \mathrm{p}<.01$, and $10 \mathrm{mg} / \mathrm{kg}, 1.58>$ $\mathrm{CR}_{\mathrm{n}-\mathrm{k}}(1.236), \mathrm{p}<.01$, morphine, when compared to saline. Animals injected with $2.5 \mathrm{mg} / \mathrm{kg}$ morphine and $1 \mathrm{mg} / \mathrm{kg}$ naloxone did not differ significantly from saline-injected animals, although the morphine difference was suggestive, $0.70<\mathrm{CR}_{\mathbf{n}-\mathbf{k}}(0.75)$, $\mathrm{p}>.05$.

The degree of analgesia present during the first postdrug test was not different from the analgesia seen during the second postdrug test. This was confirmed by the second ANOVA, which was based on difference scores between the two postdrug tests, $\mathrm{F}(4,35)=1.23$, $p>.25$. Thus, at least for the parameters of this experiment, the drug effects appear to be stable.

\section{EXPERIMENT 2}

This was a study of the antagonism of morphineinduced analgesia by various doses of the narcotic antagonist naloxone.

\section{Method}

There were four groups, each composed of eight subjects. Each group was given an initial baseline series of five flinch-jump measurements. This was followed immediately by an IP injection of $10 \mathrm{mg} / \mathrm{kg}$ morphine. Following a 30-min absorption time, a second series of flinch-jump tests was given. Immediately after this second series, one each of the four groups received IP injections of $0.01,0.1,1.0 \mathrm{mg} / \mathrm{kg}$ naloxone or of its vehicle.

\section{Results}

Baselines were very similar among the groups, and flinch thresholds did not change during the course of the experiment. Baseline jump thresholds were set at zero, and deviations from this value during the analgesia and blockade series are plotted in Figure 2.

As in Experiment 1, data analysis was in two stages. The degree of analgesia produced by morphine in the four groups was not different, $F(3.28)<1$. Pursuing the significant $F$ of the difference between analgesia 
and blockade, $F(3,28)=9.41, p<.01$, revealed the following results: $0.1 \mathrm{mg} / \mathrm{kg}, 2.18>\mathrm{CR}_{\mathrm{n}-\mathrm{k}}(1.615)$, $\mathrm{p}<.01$, and $1 \mathrm{mg} / \mathrm{kg}, 1.39>\mathrm{CR}_{\mathrm{n}-\mathrm{k}}(1.171), \mathrm{p}<.05$, of naloxone were effective in reversing the analgesia produced by $10 \mathrm{mg} / \mathrm{kg}$ of morphine, when compared to saline. Jump thresholds of animals injected with $0.01 \mathrm{mg} / \mathrm{kg}$ of naloxone were not different from saline, $.32<\mathrm{CR}_{\mathrm{n}-\mathrm{k}}(0.968), \mathrm{p}>.05$.

\section{DISCUSSION}

The flinch-jump technique has several advantages. Single-session within-subject evaluation of narcotic analgesia is possible. This was demonstrated in Experiment 1: habituation to footshock was not seen across trials. In addition, the animal does not have to be trained to respond in the flinch-jump technique. These two experiments using this paradigm demonstrate a doseresponse analgesia with $2.5,5.0$, and $10 \mathrm{mg} / \mathrm{kg}$ of morphine, and the blockade of analgesia produced by $10 \mathrm{mg} / \mathrm{kg}$ of morphine by as little as $0.1 \mathrm{mg} / \mathrm{kg}$ of naloxone. The drug-response curve for morphineinduced analgesia using the flinch-jump technique is quite similar to that employing other techniques, such as the hot plate (Hipps, Eveland, Meyer, Sherman, \& Cicero, 1976) and tail-flick (D'Amour \& Smith, 1941). The dose-response curve for the blockade of morphine-induced analgesia by naloxone is also quite similar for the flinch-jump technique and, for example, the footshock titration procedure (Markowitz, Jacobson, Bain, \& Kornetsky, 1976).

\section{REFERENCES}

Bonnet, K., \& Peterson, K. A modification of the jumpflinch technique for measuring pain sensitivity in rats.
Pharmacology, Biochemistry and Behavior, 1975, 3, 47-55.

Collins, P., WEI, E., \& WAY, E. Central sites of morphine analgesia. Proceedings of the Western Pharmacological Society, 1974, 17, 164-167.

Criswell, H. E., \& Levitt, R. A. The narcotic analgesics. In Psychopharmacology. New York: Wiley, 1975. Pp. 187-230.

D'Amour, F. E., \& Smith, D. L. A method for determining loss of pain sensation. Journal of Pharmacology and Experimental Therapeutics, 1941, 72, 24-70.

Evans, W. O. A new technique for the investigation of some analgesic drugs on a reflexive behavior in the rat. Psychopharmacologia (Berlin), 1961, 2, 318-325.

Hipps, P. P., Eveland, M. R., Meyer, E. R. Sherman, W. R., \& CICERo, T. J. Mass fragmentography of morphine: Relationship between brain levels and analgesic activity. Journal of Pharmacology and Experimental Therapeutics, 1976, 196, 642-648.

JACQUeT, Y. F., \& LAJThA, A. Morphine action at central nervous system sites in rat: Analgesia or hyperalgesia depending on site and dose. Science, 1973, 182, 490-492.

JACQUeT, Y. F., \& LAJThA, A. Paradoxical effects after microinjection of morphine in the periaqueductal gray matter in the rat. Science, 1974, 185, 1055-1057.

JAFFE, J. H. Drug addiction and drug abuse. In L. S. Goodman \& A. Gilman (Eds.), The pharmacological basis of therapeutics (5th ed.). New York: Macmillan, 1975. Pp. 284-324.

JAFFe, J. H., \& Martin, W. R. Narcotic analgesics and antagonists. In L. S. Goodman \& A. Gilman (Eds.), The pharmacological basis of therapeutics (5th ed.). New York: Macmillan, 1975. Pp. 245-283.

Markowitz, R., Jacobson, J., Bain, G., \& Kornetsky, C. Naloxone blockade of morphine analgesia: A dose-effect study of duration and magnitude. Journal of Pharmacology and Experimental Therapeutics, 1976, 199, 385-388.

Sharpe, L. G., Garnett, J., \& Cicero, T. Analgesia and hyperactivity produced by intracranial microinjections of morphine into the periaqueductal gray matter of the rat. Behavioral Biology, 1974, 11, 303-313.

(Received for publication April 12, 1977; revision accepted February 9, 1978.) 